\title{
Anti-Oxidative Constituents from Leonurii Herba (Leonurus japonicus)
}

\author{
Kazuyo Sugaya, ${ }^{1}$ Fumio Hashimoto,${ }^{1 * \dagger}$ Masateru ONO, ${ }^{2}$ Yasuyuki ITo, ${ }^{2}$ Chikako MAsuoKA ${ }^{3}$ and \\ Toshihiro NOHARA ${ }^{1}$ \\ ${ }^{1}$ Faculty of Pharmaceutical Sciences, Kumamoto University, Oe-honmachi 5-1, Kumamoto 862-0973, Japan \\ ${ }^{2}$ Research Institute of General Education, Kyushu Tokai University, Choyo 5435, Aso, Kumamoto 869-1404, Japan \\ ${ }^{3}$ School of Agriculture, Kyushu Tokai University, Choyo 5435, Aso, Kumamoto 869-1404, Japan
}

Received February 16, 1998; Accepted June 6, 1998

\begin{abstract}
Two new phenolic compounds, 1- $O$-(2,6-dimethoxy-4-hydroxyphenyl)- $\beta$-D-glucopyranoside, named leonuriside $A$ and $\beta$-(3,4-dihydroxyphenyl)-ethyl- $O$ - $\alpha$-L-arabinopyranosyl-(1 $\rightarrow 2)-\alpha$-L-rhamnopyranosyl)-(1 $\rightarrow 3$ )-D-glucopyranoside, named leonuriside B were isolated from Leonurii Herba (dried whole part of Leonurus japonicus) along with four known flavonol glycosides, rutin, isoqeurcitrin, tiliroside and isorhamnetin 3- $O$-rutinoside, and a known iridoid glycoside, leonuride. Their structures were elucidated on the basis of physical and spectroscopic data. Subsequent anti-oxidative assay of these compounds using the ferric thiocyanate method revealed that they, except for leonuride, have stronger anti-oxidative activities than that of $\alpha$-tocopherol. Moreover, the four flavonol glycosides and leonuriside $A$ were identified as stronger antioxidants than 3-tert.-butyl-4-hydroxyanisole.
\end{abstract}

Keywords: Leonurii Herba, Leonurus japonicus, Labiatae, leonuriside, anti-oxidative effect, ferric thiocyanate, leonuride

Lipid peroxidation is known as one of the major factors producing the disagreeable odor or taste in decomposing oils or fats in foods, and it could be possibly related to a cause of aging and carcinogenesis (Yagi, 1987; Hirai, 1994). Antioxidants are the major chemicals protecting cells from lipid peroxidation and for preventing foods from losing their qualities. So far synthetic (e.g. 3-tert.-butyl-4-hydroxyanisole; BHA, 3,5-di-tert-butyl-4-hydroxytoluene; BHT) and natural antioxidants (e.g. $\alpha$-tocopherol, ascorbic acid) are widely used. Although synthetic antioxidants are more active than natural antioxidants, it has become a serious problem that the former ones are reported to have toxic side effects and suspected to negatively influence human health (Ito et al, 1986). Thus, it is required to search for new types of antioxidants from nature, that are harmless to humans.

Leonurii Herba, the dried whole part of Leonurus japonicus (Labiatae) is an important herb for tonics, soothings, diuretics and stomach aches, and is also used for treating women's disorders of menstruation as an ancient Chinese crude drug. The isolations of various kinds of chemical constituents in the herb have been reported such as labdanetype diterpenoids (Wang et al., 1994; Hon et al., 1993 and 1991; Kruger \& Rivett, 1988; Malakov et al., 1985; Savona et al., 1982), flavonols (Tomás-Barberán et al., 1993 and 1992; Kartnig et al., 1985), phenylpropanoids (Calis et al., 1992), alkaloids and cyclic peptides (Kinoshita et al., 1991), and iridoids (Buzogany et al., 1983).

In the course of our studies on natural antioxidants from edible plants and crude drugs (Ono et al., 1995, 1997, 1998;

\footnotetext{
${ }^{*}$ To whom correspondence should be addressed.

†Present address: Faculty of Agriculture, Kagoshima University, Korimoto 1-21-24, Kagoshima 890-0065, Japan.
}

Masuoka et al, 1997), the methanol extract of Leonurii Herba showed potent anti-oxidative activity when compared to BHA which it has led to the isolation of seven compounds using chromatographic techniques. We now wish to report the structures of these active compounds and their antioxidative effects.

\section{Materials and Methods}

Leonurii Herba was purchased from Uchida Wakanyaku Co., Ltd., Tokyo. $\alpha$-Tocopherol and BHA were obtained from Nacalai Tesque, Inc., Kyoto. Linoleic acid was purchased from Tokyo Kasei Kogyo Co., Tokyo. The optical rotations were measured with a JASCO DIP 360 digital polarimeter (Jasco, Tokyo). The proton nuclear magnetic resonance ( $\left.{ }^{1} \mathrm{H}-\mathrm{NMR}\right)$ and carbon-13 $\left({ }^{13} \mathrm{C}\right)$-NMR spectra were recorded on JEOL JNM-GX-400 and JEOL alpha 500 spectrometers (JEOL, Tokyo); chemical shifts were given on a $\delta(\mathrm{ppm})$ scale with tetramethylsilane (TMS) as the internal standard. The mass spectrum (MS) was obtained on JEOL JMS-DX-303HF instruments. Column chromatographies were carried out with silica gel 60 (Merck, Darmstat, Germany Art. 7734 and Art. 9385), Sephadex LH-20 (Pharmacia Fine Chemicals, Uppsala, Sweden), MCI gel CHP-20P (Mitsubishi Chemical Industries, Ltd., Tokyo), and Bondapak $\mathrm{C}_{18}$ (Waters Co., Ltd., Milford, MA) with various kinds of solvent systems. Thin layer chromatography (TLC) was carried out on silica gel pre-coated Al sheets (Merck, Art. 5554).

Extraction and Isolation The Leonurii Herba (1.94 $\mathrm{kg}$ ) was extracted with $\mathrm{MeOH}(500 \mathrm{ml} \times 2)$ under reflux, and the solvent was removed under reduced pressure to yield the extract $(142.4 \mathrm{~g})$. The extract was partitioned between $n$ - 
hexane $(500 \mathrm{ml})$ and $\mathrm{H}_{2} \mathrm{O}(500 \mathrm{ml})$. The $\mathrm{H}_{2} \mathrm{O}$ layer was further partitioned with EtOAc $(500 \mathrm{ml})$. Each layer was dried under reduced pressure to furnish the EtOAc soluble fraction (fr.) (18.5 g) and $\mathrm{H}_{2} \mathrm{O}$ soluble fr. $(84.0 \mathrm{~g})$. The EtOAc soluble fr. was subjected to silica gel column chromatography $\left[\mathrm{CHCl}_{3}: \mathrm{MeOH}: \mathrm{H}_{2} \mathrm{O}(=\mathrm{C}: \mathrm{M}: \mathrm{W})=9: 1: 0.1 \rightarrow 6: 4: 1\right]$, followed by Bondapak $\mathrm{C}_{18}$ column chromatography $\left[\mathrm{H}_{2} \mathrm{O} \rightarrow \mathrm{MeOH}\right]$ to furnish compound $3(58.4 \mathrm{mg})$. The $\mathrm{H}_{2} \mathrm{O}$ soluble fr. was chromatographed over MCI gel CHP-20P $\left[\mathrm{H}_{2} \mathrm{O} \rightarrow \mathrm{MeOH}\right]$ to yield four frs. Repeated column chromatographies of these frs over Sephadex LH-20 and Bondapak $\mathrm{C}_{18} \quad\left[\mathrm{H}_{2} \mathrm{O} \rightarrow \mathrm{MeOH}\right]$ afforded compounds 1 (432.3 mg), 2 (56.7 mg), 4 (51.1 mg), 5 (17.8 mg), 6 (24.5 mg) and 7 (10.2 mg) (Fig. 1).

Leonuriside $\mathrm{A}$; $1-O$-(2,6-dimethoxy-4-hydroxyphenyl)- $\beta$ D-glucopyranoside (5): an off-white amorphous powder, $[\alpha]_{\mathrm{D}}^{26}-16.6^{\circ}(c=0.35, \mathrm{MeOH})$, positive fast atom bombardment mass spectrum (FAB-MS) $m / z: 355[\mathrm{M}+\mathrm{Na}]^{+}$. ${ }^{13} \mathrm{C}-\mathrm{NMR}$ (pyridine- $\left.d_{5}\right) \delta: 56.1\left(\mathrm{OCH}_{3}\right), 61.0($ glc(glucose)-C6), 70.0 (glc-C-4), 74.1 (glc-C-2), 76.4 (glc-C-5), 77.0 (glc-C-3), 93.8 (ag(aglycone)-C-3 and ag-C-5), 103.5 (glc-C-1), 127.4 (ag-C-1), 153.2 (ag-C-2 and ag-C-6), 153.9 (ag-C-4). ${ }^{1} \mathrm{H}-\mathrm{NMR}$ (pyridine- $d_{5}$ ) $\delta: 3.68\left(2 \times \mathrm{OCH}_{3}\right), 4.64(\mathrm{~d}, J=7.3 \mathrm{~Hz}$, glc-H-1), 6.06 (s, ag-H-4 and ag-H-6).

Leonuriside $\mathrm{B} ; \beta$-(3,4-dihydroxyphenyl)-ethyl- $O$ - $\alpha$-L-arabinopyranosyl-(1 $\rightarrow 2)$ - $\alpha$-L-rhamnopyranosyl)-( $1 \rightarrow 3$ )-D-glucopyranoside (6): an off-white amorphous powder, $[\alpha]_{\mathrm{D}}^{25}$

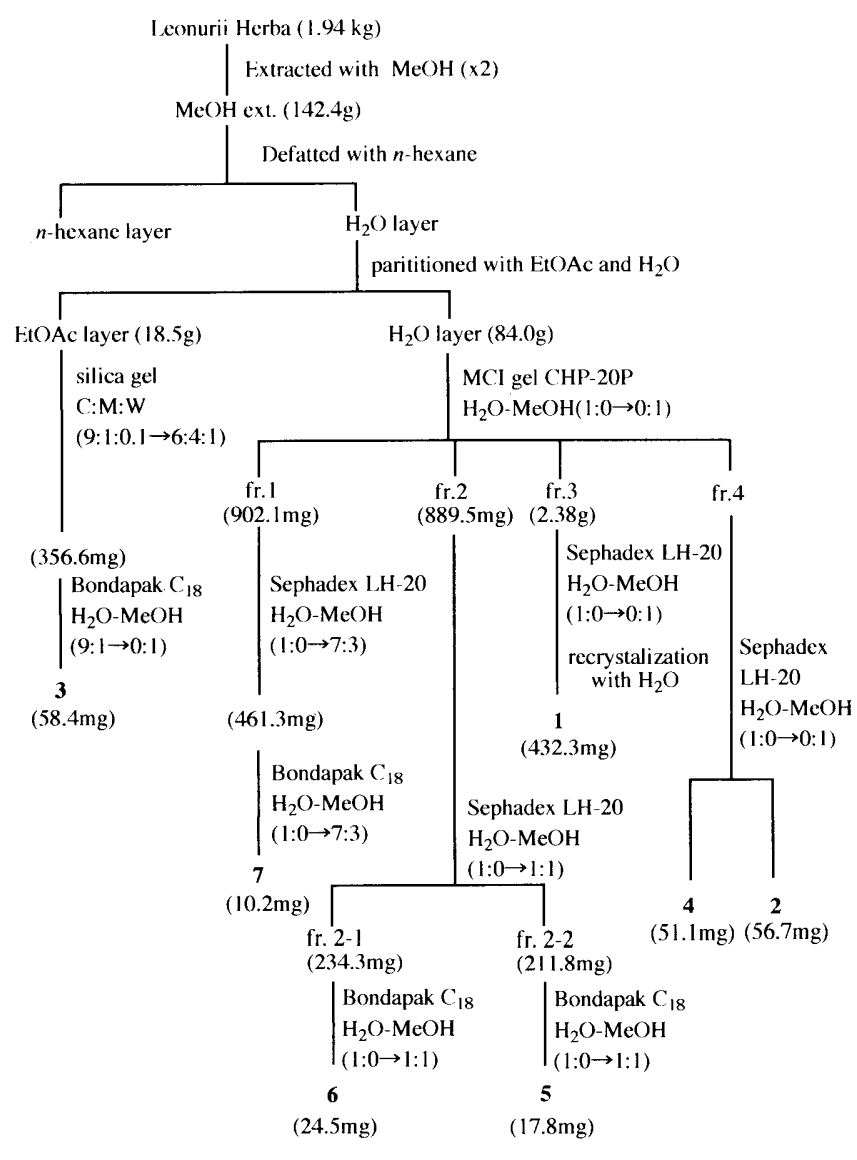

$\mathrm{C}: \mathrm{M}: \mathrm{W}=\mathrm{CHCl}_{3}: \mathrm{MeOH}: \mathrm{H}_{2} \mathrm{O}$

Fig. 1. Separation and isolation of compounds 1-7. $-26.7^{\circ}(c=0.67, \mathrm{MeOH})$, positive FAB-MS $m / z: 617[\mathrm{M}+$ $\mathrm{Na}]{ }^{+} .{ }^{13} \mathrm{C}-\mathrm{NMR}$ (pyridine- $d_{5}$ ) $\delta: 18.4$ (rha(rhamnose)-C-6), 36.1 (ag-C- $\alpha$ ), 62.4 (glc-C-6), 67.3 (ara(arabinose)-C-5), 69.4 (rha-C-5, ara-C-4), 69.6 (glc-C-4), 71.1 (ag-C- $\beta$ ), 72.9 (ara-C2), 73.1 (rha-C-3), 74.5 (rha-C-4), 74.7 (ara-C-3), 75.4 (glc-C2), 78.2 (glc-C-5), 81.9 (rha-C-2), 82.8 (glc-C-3), 101.1 (rha-C1), 104.3 (glc-C-1), 107.4 (ara-C-1), 116.4 (ag-C-5), 117.4 (ag-C-2), 120.3 (ag-C-6), 130.3 (ag-C-1), 145.5 (ag-C-3), 147.0 (ag-C-4). ${ }^{1} \mathrm{H}-\mathrm{NMR}$ (pyridine- $\left.d_{5}\right) \quad \delta: 1.63(\mathrm{~d}, J=6.1 \mathrm{~Hz}$, rha$\left.\mathrm{H}_{3}-6\right), 2.98\left(\mathrm{~m}, \mathrm{ag}-\mathrm{H}_{2}-\alpha\right), 4.77$ (d, $\left.J=7.9 \mathrm{~Hz}, \mathrm{glc}-\mathrm{H}-1\right), 5.17$ (d, $J=7.3 \mathrm{~Hz}$, ara-H-1), 6.46 (s, rha-H-1), 6.75 (br d, $J=7.9 \mathrm{~Hz}$, ag-H-6), 7.16 (d, $J=7.9 \mathrm{~Hz}$, ag-H-5), 7.21 (br s, ag-H-2). ${ }^{1} \mathrm{H}-\mathrm{NMR}$ (methanol- $\left.d_{4}\right) \delta: 1.23\left(\mathrm{~d}, J=6.1 \mathrm{~Hz}\right.$, rha- $\left.\mathrm{H}_{3}-6\right), 2.78$ (m, ag- $\left.\mathrm{H}_{2}-\alpha\right)$, ca. 3.28 (glc-H-5), 3.28 (dd, $J=7.9,9.1 \mathrm{~Hz}$, glc-H-2), 3.35 (dd, $J=9.2,9.2 \mathrm{~Hz}$, glc-H-4), 3.39 (dd, $J=9.8$, $9.8 \mathrm{~Hz}$, rha-H-4), 3.47 (dd, $J=9.2,9.2 \mathrm{~Hz}$, glc-H-3), 3.53 (dd, $J=3.7,9.2 \mathrm{~Hz}$, ara-H-3), $3.54\left(\mathrm{dd}, J=1.2,12.8 \mathrm{~Hz}\right.$, ara- $\left.\mathrm{H}_{\mathrm{a}}-5\right)$, $3.63\left(\mathrm{dd}, J=7.3,9.2 \mathrm{~Hz}\right.$, ara-H-2), ca. $3.70\left(\right.$ glc- $\mathrm{H}_{\mathrm{a}}-6$ and ag- $\left.\mathrm{H}_{\mathrm{a}}-\beta\right), 3.78$ (dd, $J=3.7,9.8 \mathrm{~Hz}$, rha-H-3), ca. 3.79 (ara-H4), ca. $3.86\left(\right.$ ara- $\left.\mathrm{H}_{\mathrm{b}}-5\right), 3.86\left(\mathrm{dd}, J=2.4,12.2 \mathrm{~Hz}\right.$, glc- $\left.\mathrm{H}_{\mathrm{b}}-6\right)$, 3.97 (m, rha-H-5), 3.99 (dd, $J=1.8,3.7 \mathrm{~Hz}$, rha-H-2), 4.03 (m, ag- $\left.\mathrm{H}_{\mathrm{b}}-\beta\right), 4.30(\mathrm{~d}, J=7.9 \mathrm{~Hz}$, glc-H-1), $4.36(\mathrm{~d}, J=7.3 \mathrm{~Hz}$, ara-H-1), 5.44 (d, $J=1.2 \mathrm{~Hz}$, rha-H-1), $6.56(\mathrm{dd}, J=1.8,8.6$ $\mathrm{Hz}$ ag-H-6), 6.68 (d, $J=8.6 \mathrm{~Hz}$, ag-H-5), 6.70 (d, $J=1.8 \mathrm{~Hz}$, ag- $\mathrm{H}-2$ ).

Leonuride (7): an off-white amorphous powder, $[\alpha]_{\mathrm{D}}^{25}$ $-139.8^{\circ}(c=1.20, \mathrm{MeOH}) .{ }^{13} \mathrm{C}-\mathrm{NMR}$ (pyridine- $\left.d_{5}\right) \quad \delta: 25.4$ (ag-C-10), 41.7 (ag-C-5), 49.7 (ag-C-7), 52.2 (ag-C-9), 62.3 (glc-C-6), 71.3 (glc-C-4), 74.9 (glc-C-2), 77.1 (ag-C-6), 78.3 (glc-C-3), 78.7 (glc-C-5), 78.8 (ag-C-8), 93.6 (ag-C-1), 99.9 (glc-C-1), 105.7 (ag-C-4), 140.1 (ag-C-3). ${ }^{1} \mathrm{H}-\mathrm{NMR}$ (pyridine$\left.d_{5}\right) \delta: 1.61(3 \mathrm{H}, \mathrm{s}, \mathrm{ag}-\mathrm{H}-8), 2.25(2 \mathrm{H}, \mathrm{m}, \mathrm{ag}-\mathrm{H}-7), 3.22$ (br. d, ag-H-5), 3.25 (br d, ag-H-9), 3.93 (m, glc-H-5), 4.04 (dd, $J=$ $7.9,8.5 \mathrm{~Hz}$, glc-H-2), 4.24 (dd, $J=8.5,8.5 \mathrm{~Hz}$, glc-H-3), 4.29 (m, ag-H-6), 4.31 (m, glc-H-4), 4.38 (dd, $J=4.8,12.2 \mathrm{~Hz}$, glc- $\left.\mathrm{H}_{\mathrm{a}}-6\right), 4.45$ (dd, $J=2.5,12.2 \mathrm{~Hz}$, glc- $\left.\mathrm{H}_{\mathrm{b}}-6\right), 4.94$ (dd, $J=$ 3.0, 6.1 Hz, ag-H-4), 5.04 (d, $J=7.9 \mathrm{~Hz}$, Glc-H-1), 6.08 (d, $J=$ $1.8 \mathrm{~Hz}$, ag-H-1), 6.42 (d, $J=6.1 \mathrm{~Hz}$, ag-H-3).

Anti-oxidative assay Anti-oxidative activity of the test sample was evaluated based on the ferric thiocyanate method (Kikuzaki \& Nakatani, 1993). The activity of the $\mathrm{MeOH}$ extract was measured at a final concentration of $0.02 \%$ as described in a previous paper (Ono et al., 1998) and a subsequent investigation for the activities of 1-6 was carried out at a final concentration of $0.5 \mathrm{mM}$ as follows. A mixture of $2.51 \%$ linoleic acid in EtOH solution $(0.80 \mathrm{ml}), 0.05 \mathrm{M}$ phosphate buffer $(\mathrm{pH} 7.0,1.60 \mathrm{ml})$ and $\mathrm{H}_{2} \mathrm{O}(0.80 \mathrm{ml})$ was added to a $2.5 \mathrm{mM}$ EtOH solution of each sample in a vial sealed with a cap and each vial was then placed in the dark at $40^{\circ} \mathrm{C}$ to accelerate the oxidation. After the 5th day of incubation, the assay solution $(0.05 \mathrm{ml})$ was diluted with $75 \%$ $\mathrm{EtOH}(4.85 \mathrm{ml})$, followed by adding $30 \%$ ammonium thiocyanate $(0.05 \mathrm{ml})$. Precisely $3 \mathrm{~min}$ after the addition of 0.02 $\mathrm{mM}$ ferrous chloride in $3.5 \%$ hydrochloric acid $(0.05 \mathrm{ml})$ to the reaction mixture, the absorbance of the developed red color was measured at $500 \mathrm{~nm}$. The control sample was prepared in the same manner by mixing all the same chemicals and ingredients and by excluding the test compounds. $\alpha$-Tocopherol and BHA were used as references. 


\section{Results and Discussion}

Leonurii Herba was extracted with $\mathrm{MeOH}$ under reflux, and the extract indicated a stronger anti-oxidative activity than BHA using linoleic acid as the substrate in the ferric thiocyanate method (Kikuzaki \& Nakatani, 1993) (Fig. 2). The extract was subjected to separation by repeated column chromatographies with various kinds of solvent systems to yield seven compounds (1-7).

Structure Elucidation of 1-7 Compounds 1, 2,3 and 4 were found to be identical with rutin, isoquercitrin, tiliroside and isorhamnetin 3-O-rutinoside, respectively, based on a comparison of the physical and spectroscopic data with

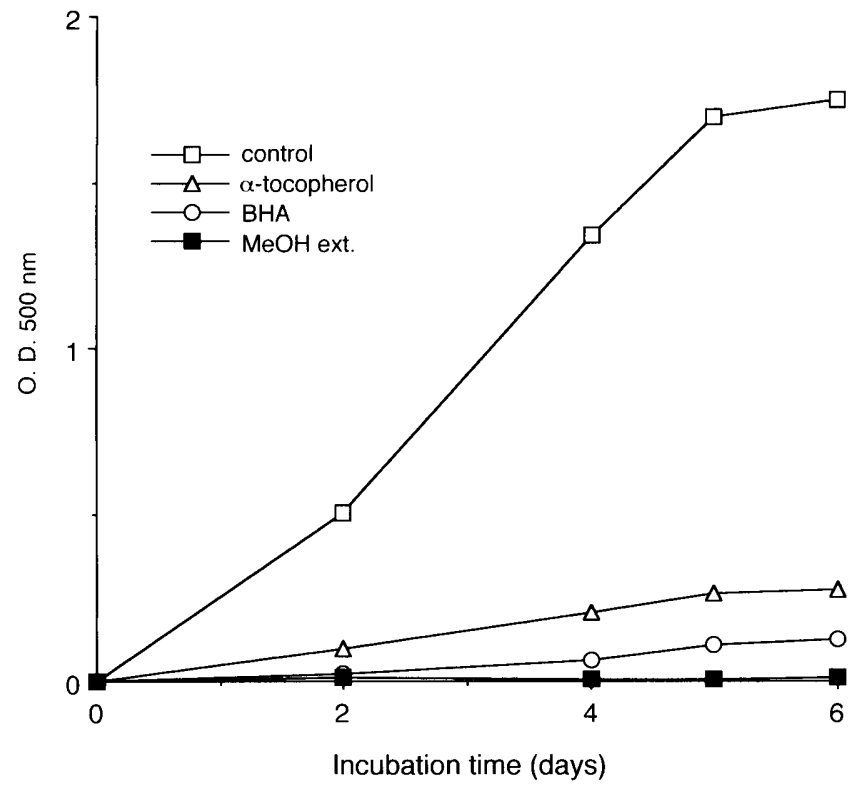

Fig. 2. Anti-oxidative activity of $\mathrm{MeOH}$ ext.<smiles>[R20]c1c(-c2ccc(O)c(Br)c2)oc2cc(O)cc(O)c2c1=O</smiles>

$\begin{array}{lll} & \mathrm{R}_{1} & \mathrm{R}_{2} \\ \text { 1: } & \mathrm{OH} & \text { rut } \\ \text { 2: } & \mathrm{OH} & \text { glu } \\ \text { 3: } & \mathrm{H} & \text { glu (2"-p-coum) } \\ \text { 4: } & \mathrm{OCH}_{3} & \text { rut }\end{array}$
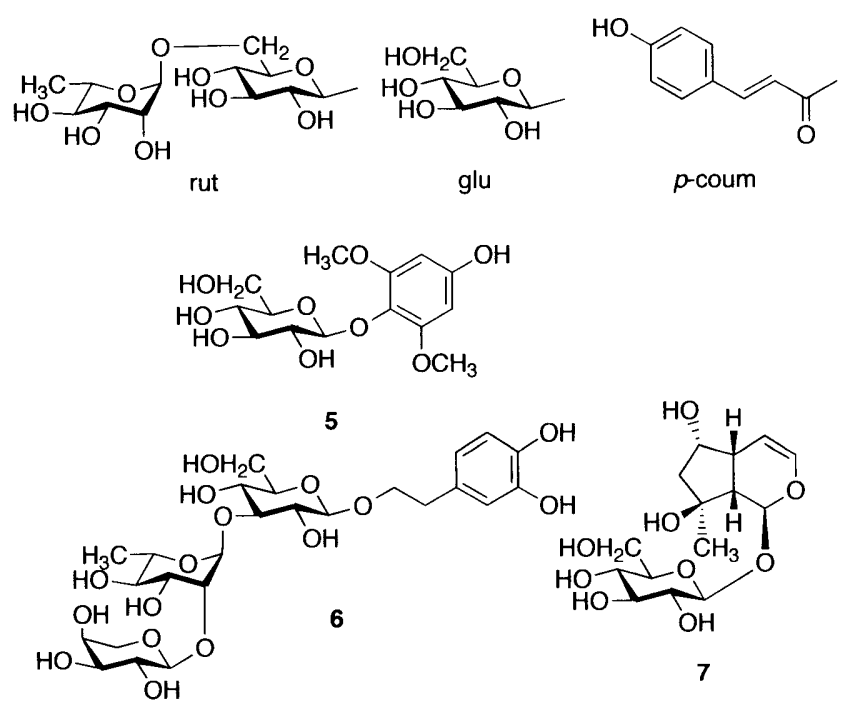

Fig. 3. Structures of 1-7. those of authentic samples and references (Harborne \& Mabry, 1982). Compound 7 was identified as leonuride on the basis of its NMR analysis (Guiso et al, 1974; Buzogany et al., 1983) (Fig. 3).

Compound 5, named leonuriside $\mathrm{A}$, was obtained as an off-white amorphous powder. Positive FAB-MS showed an $[\mathrm{M}+\mathrm{Na}]^{+}$ion peak at $m / z$ 355. In the ${ }^{1} \mathrm{H}-\mathrm{NMR}$ spectrum of 5 , present were an anomeric proton signal $(\delta 4.64)$, a singlet signal due to an equivalent of two methoxyl groups ( $\delta 3.68)$, and aromatic protons which are equivalent to two protons $(\delta$ 6.06). The ${ }^{13} \mathrm{C}-\mathrm{NMR}$ spectrum showed the presence of a glucose moiety ( $\delta 103.5,77.0,76.4,74.1,70.0$ and 61.0), an equivalent of two methoxyl carbons $(\delta 56.1)$ and aromatic carbons ( $\delta 153.9,153.2,127.4,93.8)$. Taking into account this NMR evidence, 5 was a glucoside of 2,6-dimethoxy-4 hydroxyphenol. The position of a glucose attached to aglycone was found to be in the C-1 hydroxyl group due to its ${ }^{13} \mathrm{C}$-NMR chemical shift patterns. Thus, the structure of 5 was concluded to be that shown in Fig. 3.

Compound 6, named leonuriside B, was obtained as an off-white amorphous powder, and TLC examination showed a dark green colorization after spraying with $\mathrm{FeCl}_{3}$ reagent. Positive FAB-MS showed a molecular ion peak at $m / z 617$ $[\mathrm{M}+\mathrm{Na}]^{+}$. In the ${ }^{1} \mathrm{H}-\mathrm{NMR}$ spectrum of $\mathbf{6}$, there appeared three anomeric protons ( $\delta 4.77,5.17$ and 6.46), and ABX-type aromatic protons $[\delta 6.75(\mathrm{br} \mathrm{d}, J=7.9 \mathrm{~Hz}), 7.16(\mathrm{~d}, J=7.9$ $\mathrm{Hz}$ ) and 7.21 (br s)]. The ${ }^{13} \mathrm{C}-\mathrm{NMR}$ spectrum showed the presence of a 3,4-dihydroxyphenethyl alcohol moiety ( $\delta$ $147.0,145.5,130.3,120.3,117.4,116.4,71.1,36.2)$ and three monosaccharide moieties, which were identical to the respective one molecule of glucose, rhamnose and arabinose on the basis of the ${ }^{1} \mathrm{H}-\mathrm{NMR}$ and FAB-MS data. These spectral data suggested 6 to be a deacyl derivative of lenoside A, and finally, this was confirmed by the ${ }^{1} \mathrm{H}-\mathrm{NMR}$ data when compared with those of $\beta$-(3,4-dimethoxyphenyl)-ethyl- $O$ - $\alpha$ L-arabinopyranosyl-( $1 \rightarrow 2)$ - $\alpha$-L-rhamnopyranosyl- $(1 \rightarrow 3)$-Dglucopyranoside (Calis et al, 1992). Consequently, the structure of 6 was concluded to be that shown in Fig. 3.

It should be noted that $\mathbf{5}$ and $\mathbf{6}$ are novel compounds, and the isolation of $\mathbf{4}$ is the first example from Leonurus spp.

Anti-oxidative effect of compounds 1-6 The anti-oxidative assay for 1-6 was investigated in the same manner as mentioned above. All these compounds showed stronger

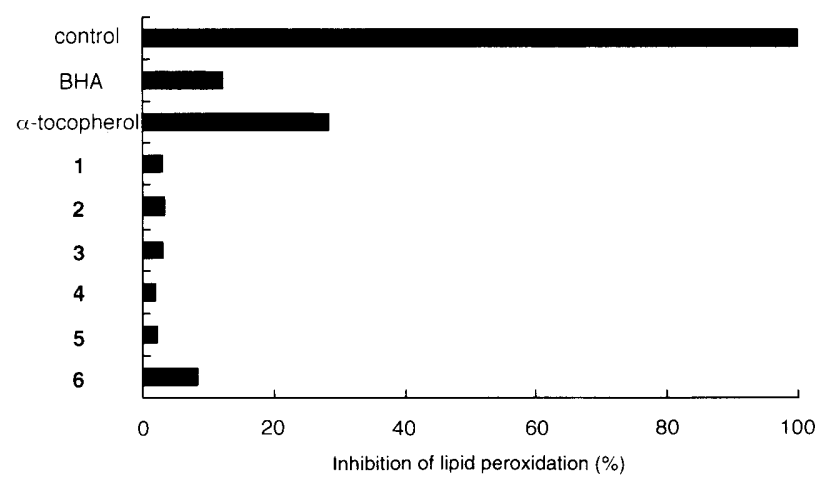

Fig. 4. Anti-oxidative activities on the 5 th day of the lipid peroxidation. 
anti-oxidative activities than those of $\alpha$-tocopherol and BHA (Fig. 4). Among them, isorhamnetin 3-O-rutinoside (4) showed a potent anti-oxidative activity that was about 6.3 times stronger than that of BHA. At a same molar concentration, 1, 2, 3 and $\mathbf{5}$ were also observed to have higher activities in the range between 3.7 and 5.3 times versus that of BHA while 6 showed activity similar to BHA. Kikuzaki and Nakatani (1993) expressed the importance of phenolic and/ or aromatic rings on which various combinations of substitutions of hydroxyl groups result to produce the anti-oxidative activity. Our recent report had substantiated these structureactivity relationships with the presence of bibenzyls, phenanthrenes and lignans in which the activities varied and depended on the positions and numbers of hydroxyl groups (Ono et al., 1995). Our experiments here showed that the active compounds 1-4 consist of a flavonol core structure with some numbers of hydroxyl groups in the A- and B-rings. Moreover, the active glycoside $\mathbf{5}$ possesses a phloroglucinol ring in which two hydroxyl groups are methylated as found in 4. Thus, it is suggested that a phloroglucinol and a catechol ring in association with methoxyl groups might seem to be one of the important structures in relation to the anti-oxidative effect.

In conclusion, 1-6 are the anti-oxidative principles in Leonurii Herba and the anti-oxidative properties of 1-6 seem to occur due to a radical scavenging effect of the phenolic hydroxyl groups.

Acknowledgements The authors are grateful to Mr. K. Takeda of Kumamoto University, Faculty of Pharmaceutical Sciences, for the NMR spectral measurements, and also to $\mathrm{Mr}$. T. Iriguchi for the positive FAB-MS measurements.

\section{References}

Buzogany, K. and Cucu, V. (1983). Studi comparativ intre speciile Leonurus cardiaca L. si Leonurus quinquelobatus Gilib. II. Continutul in iridoide. Clujul medical, LVI, 385-388.

Calis, I., Ersöz, T., Tasdemir, D. and Rüedi, P. (1992). Two phenylpropanoid glycosides from Leonurus glaucescens. Phytochemistry, 31, 357-359.

Guiso, M., Marini-Bettolo, R. and Agostini, A. (1974). 4/Iridoids -XIII: Ajugoside and ajugol: Structure and configuration. Gazzetta Chim. Ital., 104, 25-33.

Harborne, J.B. and Mabry, T.J. (1982). "The flavonoids: advances in research." Chapman and Hall, pp. 84, 91, 92, 99.

Hirai, S. (1994). Rouka to kousankazai. In "antioxidants (free radicals and biological defense)" ed. by E. Niki, H. Shimasaki and M. Mino.
Japan Scientific Societies Press, Tokyo, pp. 317-327.

Hon, P.-M., Lee, C.-M., Shang, H.-S., Cui, Y.-X., Wong, H.N.C. and Chang, H.-M. (1991). Prehispanolone, a labdane diterpene from Leonurus heterophyllus. Phytochemistry, 30, 354-356.

Hon, P.M., Wang, E.S., Lam, S.K.M., Choy, Y.M., Lee, C.M. and Wong, H.N.C. (1993). Preleoheterin and leoheterin, two labdane diterpenes from Leonurus heterophyllus. Phytochemistry, 33, 639641.

Ito, N., Hirose, M., Fukushima, S., Tsuda, H., Shirai, T. and Tatematsu, M. (1986). Studies on antioxidants: Their carcinogenic and modifying effects on chemical carcinogenesis. Food Chem. Toxicol. 24, 1099-1102.

Kartnig, T., Gruber, A. and Menzinger, S. (1985). Flavonoid- $O$ glycoside from the herbs of Leonurus cardiaca. J. Natur. Prod., 48 494-507.

Kikuzaki, H. and Nakatani, N. (1993). Antioxidant effects of some ginger constituents. J. Food Sci, 58, 1407-1410.

Kinoshita, K., Tanaka, J., Kuroda, K., Koyama, K., Natori, S. and Kinoshita, T. (1991). Cycloleonurinin, a cyclic peptide from Leonuri Fructus. Chem. Pharm. Bull., 39, 712-715.

Kruger, G.J. and Rivett, D.E.A. (1988). Diterpenoids of Leonotis species. Part 7. The crystal and molecular structure of compound X, a labdane from L. leonurus. S.-Afr. Tydskr. Chem., 4, 124-125.

Malakov, P., Papanov, G., Jakupovic, J., Grenz, M. and Bohlmann, F. (1985). The structure of leocardin, two epimers of a diterpenoid from Leonurus cardiaca. Phytochemistry, 24, 2341-2343.

Masuoka, C., Ono, M., Ito, Y. and Nohara, T. (1997). Antioxidative constituents from the aerial part of Piper elongatum VAHL. Food Sci. Technol. Int. Tokyo, 3, 285-289.

Ono, M., Ito, Y., Masuoka, C., Koga, H. and Nohara, T. (1995). Antioxidative Constituents from Dendrobii Herba (Stems of Dendrobium spp.). Food Sci. Technol., Int., 1, 115-120.

Ono, M., Masuoka, C., Ito, Y., Niiho, Y., Kinjo, J. and Nohara, T. (1997). Antioxidative and antihyaluronidase activities of some constituents from Foeniculi Fructus (fruit of Foeniculum vulgare MiLLeR). Food Sci. Technol. Int. Tokyo, 3, 53-55.

Ono, M., Masuoka, C., Ito, Y. and Nohara, T. (1998). Antioxidative Constituents from Viticis trifoliae Fructus (Fruit of Vitex rotundifolia L.). Food Sci. Technol. Int. Tokyo, 4, 9-13.

Savona, G., Piozzo, F., Bruno, M. and Rodriguez, B. (1982). Diterpenoids from Leonurus sibiricus. Phytochemistry, 21, 2699-2701.

Tomâs-Barberån, F.A., Gil, M.I., Ferreres, F. and Tomás-Lorente, F. (1992). Flavonoid $p$-coumaroylglucoside and 8-hydroxyflavone allosylglucosides in some Labiatae. Phytochemistry, 31, 3097-3102.

Tomás-Barberán, F., Krestovskaya, T. and Gil, M.I. (1993). Flavonoid p-coumaroylglucosides in some Leonurus, Chaiturus and Panzerina species (Lamiaceae). Biochem. Sys. Ecol., 21, 531-532.

Wang, E.S., Luo, B.S., Mak, T.C.W., Choy, Y.M. and Wong, H.N.C. (1994). Model study and partial synthesis of prehipanolone and 14 15-dihydroprehispanolone from hispanolone. Tetrahedron Lett., 35, 7401-7404.

Yagi, K. (1987). Lipid peroxides and human disease. Chem. Phys. Lipids, 45, 337-341. 